\title{
Communications
}

2015; 3(5): 93-101

Published online August 11, 2015 (http://www.sciencepublishinggroup.com/j/com)

doi: $10.11648 /$ j.com.20150305.13

ISSN: 2328-5966 (Print); ISSN: 2328-5923 (Online)

\section{Workplace Oral and Written Language Needs for Graduate Students: A Review}

\author{
Seyed Mohammad Mohammadi ${ }^{1, ~ *, ~ M a n i j e h ~ M a s o u d i ~ M o g h a d a m ² ~}$ \\ ${ }^{1}$ Faculty of Humanities, Kharazmi University, Tehran, Iran \\ ${ }^{2}$ Faculty of Continuing Education and Training, Seneca College, Toronto, Canada \\ Email address: \\ Mado.enaj@yahoo.com (S. M. Mohammadi), manije4414@yahoo.com (M. M. Moghadam)
}

\section{To cite this article:}

Seyed Mohammad Mohammadi, Manijeh Masoudi Moghadam. Workplace Oral and Written Language Needs for Graduate Students: A Review. Communications. Vol. 3, No. 5, 2015, pp. 93-101. doi: 10.11648/j.com.20150305.13

\begin{abstract}
Literature on Language for Specific Purposes (LSP) and English for Specific Purposes (ESP) has shown that individuals working in a particular context have specific needs or are expected to have specific skills in a particular language, and that the language used at work often differs from that used in other contexts. As such, this study tried to review the oral as well as written needs of language users in the context of workplaces. To do this end, an interview protocol was used which consisted of 15 semi-structured questions. In addition to the interviews with graduates, 15 of their workplace supervisors were also interviewed via the telephone to gather details of the company communication profiles and to obtain their views about the graduates' particular communication needs. Furthermore, some authentic workplace texts were collected and several programmed visits to workplaces were undertaken thereof. The findings confirm that foreign language skills are an increasingly important basic component of professional academic skills, particularly in countries which have major business contacts with the world and their native languages are not among the major world languages. The surveys indicated that there were substantial uses of English, but with far greater use of written compared with spoken English. Close co-operation with employers in planning language courses is thus needed in order to tailor language teaching to adequately meet the needs of the future academic workforce.
\end{abstract}

Keywords: LSP, ESP, Written, Context, Language Skill

\section{Introduction}

Language teaching courses in LSP/ESP are therefore targeted at a specific group with particular needs. The LSP/ESP approach, often focusing on the business context and employing methodology that often stems from genre or discourse analysis, offers us invaluable insight into the language needed at work. However, our approach is different. One of the inherent problems in language teaching at university language centers is not knowing enough about the students' future careers and language skills needed at work, so we concentrate on the "common core" of the workplace to help teachers plan courses for students from many different disciplines.

Although there have been an increasing number of studies related to workplace English, this body of knowledge into the language of the workplace is growing and many scholars $(\mathrm{St}$ John, 1996; Swales, 2000; Hewings, 2002) have pointed out that it is still rather limited compared to many other well- researched applied linguistic areas of study.

In recent years calls have been made for graduates to be proficient in oral communication skills so that they can function effectively in the workplace. Despite the need, and the varied and often creative ways of including oral communication skills in subjects, there appears to be little research available that provides precise understandings of the nature of workplace communication for graduate employees.

For example, Crosling and Ward (2002) analyzed the development of oral communication skills in an undergraduate business and commerce curriculum and argued that undergraduate experience in formal presentation only can be a sign of insufficient preparation for oral communication in the workplace.

Moreover, workplace discourse can reflect power relations (Fairclough, 1995). Regarding the social context of workplace communication, one can point to the language specimens in social contexts for purposes of professional communication such as power (Foucault, 1982; Bourdieu \& 
Wacquant, 1992; Habermas, 1987; Cicourel, 1992; Fairclough, 1995; Martin \& Rose, 2002:254).

English in the Workplace (EWP) is a dynamic form of language instruction. It requires instructors to capture and maintain learner attention to produce results in a much shorter period of time than regular ESL courses. Consequently, an instructor succeeds when he/she is able to prioritize the most important learning outcomes and tries to achieve them. He/she also needs to display adaptability, flexibility, discretion, and empathy while teaching and working with the organization.

In a similar vein, Moslehifar and Ibrahim (2012)reports on an investigation of English Language Oral Communication (ELOC) needs of HRD undergraduates from a public university in the Southern part of Malaysia and concluded that there were some specific oral communicative events and skills required by HRD trainees at the workplace.

The following review attempts to compare EWP programs in different countries with different language settings and policies.

\section{A) Finland}

One study was conducted within the context of the Language Center of the University of Helsinki, Finland. The Language Center, a large independent teaching unit, caters for students from eleven different faculties and provides them with opportunities to fulfill the degree requirements in languages.

Finland is a bilingual country (Finnish/Swedish), with a $5.5 \%$ Swedish-speaking minority geographically clustered in the coastal areas of the country. Finnish and Swedish are not related languages. Employees in the public sector are required by law to be able to function in the two official languages of Finland, and thus graduates working in the public sector are required to have a good knowledge of both languages.

In addition to the need for Finnish and Swedish, there is an apparent need for English at work, and the knowledge of some other foreign languages is normally assumed to be a bonus. The skills in English are normally estimated to be relatively good, but knowledge of other foreign languages seems to be declining.

According to the government decree on university degrees in Finland (2004), all university graduates are required to show they are proficient in both official languages of the country and at least one foreign language. The decree states that, in addition to gaining language skills relevant to his/her field, the graduate should be able to operate in an international environment in a foreign language.

A project called Language Needs at the Workplace was launched at the Language Center of the University of Helsinki in 2003. The aim was to investigate the actual language use of employees with an academic degree and to interview representatives of employers about issues related to language use.

The project consisted of two parts, a postal survey to employees and interviews with employers. First, Horppu and Niskanen (2004) carried out a postal survey (structured questionnaire) on the actual use of languages at work, and the frequency and type of usage five years after graduation. The survey was sent to 2474 and returned by 1190 graduates of the year 1999 from the University of Helsinki. The respondents represented all faculties, and the response rate was highest among those who graduated from the faculties of Science (52\%), Behavioral Sciences (51\%) and Arts (50\%). findings suggest that English is needed on a regular basis, and about a third of the Finnish-speaking respondents use Swedish regularly. Almost all Swedish-speaking graduates, however, responded that they use Finnish regularly.

Moreover, an earlier study had revealed that well over $90 \%$ of all graduates from 1999 and 2001 had fulfilled the degree requirement in English. Second, the employer interviews were collected in the spring of 2005 in and around Helsinki, Finland. 19 staff members involved in recruitment or personnel management for 15 employers were interviewed. The interviews dealt with various matters related to foreign language use and need at work. These 15 employers represented the sectors that employ university graduates: town councils, state offices, universities or other institutions of higher education, the Lutheran church of Finland, i.e. the predominant religious community, NGOs, and private or state-owned companies (employers in the fields of law, pharmaceuticals, paper, insurance, publishing and broadcasting).

The general message received from the employers was that, today, language skills are important in professions requiring university education. In fact, these skills are often regarded as self-evident, and job applicants with a poor knowledge of languages are not even considered. Furthermore, language skills may be decisive in recruitment, if applicants are otherwise very even. All interviewees named Finnish, Swedish and English as languages used in their contexts. English, in particular, was considered important in all sectors (in addition to the majority language, Finnish). When discussing the use of English, the interviewees underlined the importance of its fluent use in professional matters.

In official European Council documentation (e.g. Commission of the European Communities, 2003), the aim is for all Europeans to be able to use their mother tongue and two other languages. In the Finnish workplace context in general, based on our data, the three most important languages are Finnish, English and Swedish. According to European Commission, 2006, Finns state they know English (63\%), Swedish (41\%) and German (18\%) well enough to have a conversation. The need for languages other than Finnish, Swedish and English is relatively difficult to assess, but the interviewees gave context-specific examples of their use. However, no language was singled out, although there were mentions of the need for languages such as Spanish, German, French, Russian and Estonian.

The employers' definitions of good language skills in their work context were similar, regardless of the sector the employer represented. As indicators of good language skills the employers included good communication and 
presentation skills, confidence to use a foreign language, and the ability to interact and adapt to various linguistic and cultural conditions.

The interviewees stated that a language has to be at a high level in order for it to bear any proper relevance. They mentioned several high-level receptive and productive tasks that employees need to perform, such as negotiating, giving and attending lectures and presentations, writing up contracts and drafting project plans.

The interviewees also discussed issues related to culture. The focus of professionals at the workplace seems to be on smooth communication in context and on cooperation with people from other cultures, often in a lingua franca. As today's workplaces for graduates in Finland are often multilingual, cultural competence or "multicultural survival skills" have become increasingly important.

This research showed a picture of a workplace that regards foreign language skills as a basic requirement and sets high demands on language skills. Subject expertise alone is no longer sufficient. What is integral is the ability to communicate this expertise in one's mother tongue and also in other languages in speaking and writing. This is especially true in Finland, whose national languages is not widely used in international terms, and may well be true in other countries similar to Finland.

The European policies which promote the knowledge of one's mother tongue plus two additional languages also seem to reflect the needs of the workplace in the sense that languages are not necessarily used separately but often in conjunction with other languages in any one particular situation. The interviewees implied that a person might make use of more than one foreign language in a particular situation or in a particular job and that skills in these languages may vary.

Since the task of the University is to prepare students for real life after studies, language educators perhaps need to pay more attention to the needs of the workplace. As shown in this research, the skills needed at work are at a high level: an employee needs to carry out complicated tasks using complicated language. This means not only basic communication but communication in highly demanding workplace-related situations should be the target of language courses that prepare students for life after studies.

The interviewees referred to levels equivalent to B2, C1 and $\mathrm{C} 2$, when discussing good language skills. If these indeed are the levels of proficiency expected, language teaching should not only pay attention to communication, but also to aspects such as vocabulary range, pronunciation and accuracy, to help learners who are already good communicators to become even better.

Instead of placing emphasis on professional language skills, language teaching in Finnish language centers is often more geared towards academic language skills such as academic reading, writing and presentation. This is understandable, because students need language skills in their studies as well, and language courses that meet the degree requirements generally form a very small part of all the credits needed. However, a professionally relevant language dimension should also be part of all university degrees.

One of the messages to language educators in Finland is that there is a correlation between languages taught and known, and the languages actually used at work. The languages that are most often taught in the Finnish school system and in the university language centers are those used at the workplace, but the need for English by far exceeds the need for the other languages that have been studied. If languages that are not needed as often as English are to be promoted, university students must gain good skills in these additional languages in order to function well in demanding settings.

\section{B) Malaysia}

In the context of workplace communication, having good communication skills is the way to success and that good communication skills are seen as fundamental and an additional advantage. In the perspective of Stivers, Campbell and Hermanson (2000), oral communication skill in English is an important skill for managers to possess in order to carry out tasks efficiently at the workplace. In a study by Kassim and Ali (2010), the significant role of oral communication skills in multinational companies was reported by between 71 to 80 percent of the respondents. They ranked the usage of oral communication skills in multinational companies as follows; telephone conversation, informal work related discussions, meetings, giving oral presentations, explaining and demonstrating to subordinates and other colleagues. Higher Institutions in Malaysia are seeking to generate creative managers in different fields to meet the needs of thriving resources in various situations. In fact, at present, one of the key objectives in Malaysian higher institutions is to generate large number of graduates with high ability to communicate effectively at the workplace. To achieve this goal, higher institutions are attempting to design language programs with a focus on communicative skills.

Blair and Jeanson (1995) believe that, a high proficiency in English language, especially in oral communication skills would be valuable to solve different problems that take place in workplace situations. Unfortunately, despite the professional and formal training given to students and graduates, there is still a skill gap in workplace situations. It is mentioned that there are significant gaps between the expectations of industries and what the universities offer to the students.

Human Resource management (HRM) is one of the demanding sectors of management in Malaysia. Drafting, interviewing and hiring new staff are responsibilities of these managers. However, since the role of English as the global language or lingua franca in both multinational and many local companies in Malaysia has increased dramatically, HR managers now must be able to communicate effectively more than what was expected of them in the past both inside and outside the workplace. Thus, employers find themselves in circumstances in which the ability to communicate well is crucial in order to function effectively at the workplace. 
Furthermore, HRM related work involves a variety of activities. The main activity involves making decisions on the needs of the company; for example, whether to use independent suppliers or hire employees to fill these needs. Kassim and Ali (2010), however, reported that many staff, including those in the HRD sector, face problems in communicating well in English and often encounter problems speaking fluently in meetings, delivering public speaking and giving oral presentations. The aforementioned study was conducted on HR multinational companies in Malaysia to examine their English communication needs.

The findings of the study highlighted the need for graduates to equip themselves with oral communication skills to ensure that they can function effectively at the workplace. Previous discussions have shown that communication problems at the workplace are related to low proficiency in English language and the skill gaps between the expectations of industries and what the universities offer to the students. The problems faced by existing staff in multinational companies include difficulty in expressing views and ideas at the workplace by nonnative speakers of English.

In this research, a questionnaire as the data collection instrument was utilized which was adopted from questionnaires used in two previous needs analysis studies. The first is a study on the needs analysis of the English communication skills of final year Electrical Engineering undergraduates in Universiti Teknologi Malaysia, the same university in which this study was undertaken. The second study is on the oral communication skills in English which focused on matching the skills developed at the university with the need and demand of the Industry.

The important activities in English language included:

1 Discussing projects, proposals, Plans and designs

2 Reporting problems

3 Making formal oral presentations on projects, proposals, plans, and designs

4 Making and arguing for an issue before superiors or colleagues

5 Giving face-to-face instructions to subordinates

6 Speaking on the telephone with colleagues about job related matters

7 Speaking on the telephone with clients about job related matters

8 Establishing social relationships with colleagues (including subordinates and superior)

9 Establishing social relationships with clients

10 Providing training through discussions and workshops

In addition, encountering problems during the practical training included:

1 Arguing persuasively

2 Explaining logically

3 Speaking fluently

4 Supporting opinions

5 Asking for clarifications

6 Giving clarifications

7 Paraphrasing

8 Facilitating discussions/negotiations
9 Organizing ideas during oral presentations

10 Giving an oral presentations

Finally the overall emphasis on oral communication skills for future HRD trainees was decided to be:

1 Oral presentation skills

2 Discussion skills

3 Negotiation skills

4 Briefing skills

5 Meetings

6 Telephone skills

7 Conversation skills

8 Pronunciations

Another study describes an effort to identify and evaluate the needs of engineering students with the hope of providing appropriate communication skills needed at the workplace. In today's most competitive world, engineers are not only required to effectively convey technical information, but they also need to have acceptable social and communication skills in order to excel in the workplace. Unfortunately, there is significant evidence that shows an inadequacy among graduating engineers to meet these requirements. This scenario has resulted in collaboration between engineering education, the industry and communication educators.

This study utilized a self-developed survey questionnaire to identify the English language skills and the communicative events in which English was mostly used by engineering employees. The information for the development of the survey questionnaire was collected based on: (1) reference to previous studies on needs analysis, (2) feedback from informal verbal discussions and through emails with a number of engineers and human resources managers from the industries within the university's network, (3) feedback from informal interviews and discussions with the engineering lecturers in the faculties, and (4) teaching experiences at the university.

The participants were engineers from 10 multinational chemical companies in Malaysia. The survey questionnaire was divided into two sections. Section A inquired about the demographic information of the engineers, background information of their experiences at their respective companies and some basic information about the company they worked for. Section B aimed to investigate the oral communication skills used by the engineers and the communicative events they were involved in, at their workplaces.

The need to know what is actually being practiced in the engineering workplace will definitely help educators, language practitioners, and content developers to prepare their students to face the working world. Therefore, the scope of the study included all four language skills: reading, writing, speaking and listening, with strong emphasis on the productive skills: writing and speaking. The informal interviews with the engineers and the engineering lecturers, however, suggested that speaking skills need to be more accentuated in classroom activities than written skills. Moreover, speaking or oral communication skills should be given higher priority compared to the other skills, since many surveys conducted with employers have shown that oral communication is the key skill looked for by employers and many new local 
undergraduates lack this skill.

oral communication skills is defined by referring to all skills which are used when communicating verbally, which may include appropriate use of body language and correct intonation or pronunciation. On the other hand, communicative events refer to happenings and occurrences in engineering work settings where employees have to communicate using English; for example, resolving conflict or giving an oral presentation. Therefore, identifying appropriate oral communication skills and communicative events through a needs analysis is essential as it would assist us to inform language practitioners, syllabus designers and module developers of suitable work-related content.

The 65 respondents were all engineers from different engineering fields and included Process Engineers, Electrical Engineers, Instrument Engineers, Mechanical Engineers, Heads of Inspection, Senior Engineers, Quality System Engineers, Operation Engineers, Operation Associate Engineers, Project Engineers and Process Control Engineers. As a team, different types of engineers are needed to handle a project, therefore, a diversity of engineers are present at any one time in the petrochemical industry. Although the focus of the inquiry was the petrochemical industry, we found that the engineers were not only from the chemical engineering field, but also from other engineering fields, namely mechanical engineering and electrical and electronics engineering. This is not uncommon since most engineering disciplines are bound to be interrelated and intertwined at some point or another.

The current communication syllabi used at that university, which include courses such as English for Academic Communication, Technical Communication, Business Communication and Professional Communication emphasizes the productive skills: writing and speaking, with embedded teaching of grammatical elements. Less emphasis is placed on reading and listening skills, as these activities are mostly carried out independently by the students through self-access activities using procured language software. Therefore, in order to ensure that the syllabi we have been using provide learners with the industry's actual needs, the researchers requested the engineers to rate the importance of the four basic language skills: writing, reading, speaking and listening, in the engineering workplace. They mentioned that more focus and stress should be given to the productive skills.

The following list displays the lists of communicative events in which English oral communication skills were required of the engineers.

1 Discussing work-related matters informally

2 Discussing work-related matters formally

3 Teleconferencing

4 Conversing informally and socially

5 Giving oral presentations

6 Networking: developing contacts for advice and information

7 Instructing, explaining and demonstrating

8 Communicating via telephone

9 Presenting new ideas/alternative strategies

10 Building relationships

11 Handling external correspondence

12 Resolving conflict

13 Negotiating with team members

14 Working in a team

The engineers were also asked to provide opinions regarding the advantages of having good English communication skills. About 27 responses were received, and the following table lists all the responses which have been categorized into five themes. The engineers believed that with excellent fluency in English language, opportunities to become global engineers, to advance their career, and to develop their attitude and aptitude professionally in the workplace were very high. Moreover, the dominance of English as an international language in many sectors, including the engineering industry, makes it a necessity for all engineers to use it as a tool for self and professional development and also as a communication tool.

Table 1. Advantages of having good English communication skills.

\begin{tabular}{|c|c|}
\hline Themes & Responses \\
\hline \multirow[t]{6}{*}{ To become global engineers } & 1- English as an international language understood by most engineering communities \\
\hline & 2- Important skill in any international company and national company \\
\hline & 3- English communication skills dominant in engineering activities \\
\hline & 4- Can work with multinational company and used to communicate with clients or international staff \\
\hline & 5- To be competitive in this global area \\
\hline & 6- As global players \\
\hline \multirow[t]{3}{*}{ To advance in one's career } & 1- Career advancement/promotion \\
\hline & 2- Chance for workplace survival \\
\hline & 3- To perform duty as workers \\
\hline \multirow[t]{6}{*}{ To develop one's professionalism } & 1- To be able to participate in all activities \\
\hline & 2- Help to earn respect in workplace \\
\hline & 3- Build up confidence handling problems \\
\hline & 4- The power of influencing people to agree with you in an argument or proposal \\
\hline & 5- Better project presentations \\
\hline & 6- Build good relationships \\
\hline \multirow[t]{3}{*}{ To communicate effectively } & 1- Faster response and accurate email communication \\
\hline & 2- Information sharing \\
\hline & 3- The medium of communication in daily activities \\
\hline
\end{tabular}




\begin{tabular}{ll}
\hline Themes & Responses \\
\hline & 4- Easy to give and receive information \\
& 5- Understand instructions \\
6-Convincing communication and effective report writing & 1- Most engineering terms are in English \\
2- All meetings are conducted in English \\
3- Standard procedures are all in English \\
4- English is used for business communication \\
5- Most joint-venture companies use English \\
6- Everything important is in English \\
\hline
\end{tabular}

\section{C) Germany}

Edwards, N. (2000) conducted an ESP case study which took place in a specialized business context involving senior German bankers. The socio-cultural context of the course involved three German officials at the German Central Bank in Frankfurt, one man and two women in their early thirties. One woman analyzed economic data and compiled statistics. The other woman worked as an adviser in a special financial department, and the man was primarily involved in meeting and negotiating with foreign banking officials. They had studied English at the university level, and had an impressive vocabulary and store of idioms, although these were not always used appropriately or in a native-like way. The ESP class took place twice a week in the morning at 10 and lasted for two 45 min periods in a large meeting room at the bank. Initially, the course was to last for three months but this was eventually extended to more than a year. The initial course aims and objectives were determined by a personal interview with the employer and by a brief needs analysis. One important aim of the course was to improve the students' spoken English used in business meetings and negotiations. The second important aim was training on giving presentations using different kinds of graphs and charts. The course also worked on improving the skills of writing reports, reading short articles related to banking, and listening to language used by native speakers in meetings and small talk. Another aim was to build both general and specialist vocabulary. The most important overall objective of the course was to improve the speaking confidence of the students, especially that of the women, when functioning in a native-speaker environment. During the course the students were asked for their valuable feedback and opinions on the exercises used, as well as about the general direction of the course. A flexible and multi-layered syllabus which consisted of three sections: functions, topics, and vocabulary was used. Selectively exploiting and supplementing ready-made materials saved valuable time while providing the students with the language skills they required. The overall approach to the course which Edwards adopted was essentially topdown in nature. It focused more on meaning than on form, on communicating and articulating ideas in meaningful contexts and drawing on background knowledge or content schemata, rather than simply decoding decontextualized basic, individual grammatical units at the sentence level. Communicative information-gap and opinion-gap exercises in which the students had to find information in order to complete financial statements and reports were employed. Jumbled texts were used to show the paragraph structure of various reports and business letters. Jumbled sentences were used to help students become familiar with the discourse patterns of language used to conduct business meetings, to negotiate and to engage in small talk. Charts, graphs, tables and summaries of statistics and trends in financial reports were used to practice scanning for information. Short articles dealing with economics or banking were selected from various magazines such as The Economist and used in a text presentation in which the students had to identify the functions of different cohesive devices or discourse markers with minimal guidance on my part. These articles and reports were used to practice skimming for information and to read carefully for detailed comprehension.

The students were often required to guess the meaning of new vocabulary based on the context, clues in the surrounding text, or on cognate roots. A variety of vocabulary exercises including matching words and phrases with pictures, finding opposites and synonyms, crossword puzzles and supplying the words in blank speech bubbles were used. The students were asked to record new vocabulary along with example sentences to aid them in remembering the new words. Short vocabulary quizzes were held orally in the beginning of each class in order to recycle previously learnt vocabulary and key words from past articles and discussions. Some class discussions and role plays simulating a meeting or negotiation were taperecorded. The students were then asked to evaluate their own performance. In addition to the material used in the three core textbooks mentioned, various authentic materials were exploited to make the course more interesting and relevant. Articles were regularly selected from newspapers such as The Guardian, The Times, and The New York Times. Articles on general financial and banking matters of current interest were also taken from international magazines such as The Economist and Time. A bilingual magazine called Spotlight, with useful footnotes on key vocabulary items and authentic interview transcripts, was also used. The students themselves and their vast accumulated store of subject matter knowledge constituted the most valuable source of course material. Edwards was not allowed to observe bankers while working. He was also unable to record any of the students English telephone conversations or to obtain copies of authentic internal memos, faxes, and business letters or E-mail messages for reasons of tight security. Test results, 
discussions, interviews and informal means had been used to assess the course. Frequent informal testing in the form of role plays, presentations, and discussions in class all demonstrated improvement in fluency and speaking confidence. The necessities, lacks, wants, and learning needs of the students were all considered and addressed in the course.

\section{D) Hong Kong}

Another study was conducted to investigate the workplace English needs of textile and clothing merchandisers in Hong Kong who communicate in the international marketplace. Given the importance of the industry to the Hong Kong economy, and the increasingly competitive and changing demands of the global marketplace, it is essential that workers become fluent and accurate in English usage. The subjects of the study were 360 graduates from two Hong Kong institutions, namely: The Hong Kong Polytechnic University (PolyU) and the Kwun Tong Technical Institute (KTTI).

A merchandiser requires considerable business communication skills in addition to specialist technical knowledge and his/her role as a junior or middle manager whose responsibility is mainly the marketing and financial side of the buying/selection operation, quantities, size breakdown, distribution, contracts, etc. The position of merchandiser normally involves communication with several customers and may include:

1 the buyer who places the order for a consignment of garments;

2 the supplier of fabric, yarn and accessories;

3 the manufacturer/factory involved in producing the garments.

Since the buyers, suppliers and manufacturers are normally based in different countries, it is frequently necessary for the merchandiser to communicate with the different parties in the international language of business, English.

The design of this needs analysis has been largely influenced by the work of Hutchinson and Waters. They define needs in terms of target needs (i.e. what the learner needs to do in the target situation) and learning needs (i.e. what the learner needs to do in order to learn).

The target needs are further broken down into the necessities, wants and lacks of the students and these have been investigated by using all of the standard data collection methods listed by Hutchinson and Waters. Questionnaires, follow-up telephone interviews, collection of authentic workplace texts, and visits to the workplace all contributed to the data collection. The questionnaires revealed results about the following:

1 the extent of English usage;

2 the countries with which business is conducted;

3 the most common channel(s) of communication;

4 the most preferred channel(s) of communication;

5 the main purpose(s) of written communication;

6 the use of abbreviations in written messages.

\section{Techniques Used to Gather Data}

\subsection{Telephone Interviews}

Telephone interviews were used to follow up on the questionnaire responses of 18 of the KTTI graduates. The interviews were conducted in Cantonese, the first language of the subjects and the KTTI investigator. An interview protocol was used which consisted of 15 semi-structured questions. In addition to the interviews with graduates, 15 of their workplace supervisors were also interviewed via the telephone to gather details of the company communication profiles and to obtain their views about the graduates' particular communication needs. These interviews, with both the graduates and their supervisors, were used to supplement the information obtained via the questionnaire in order to achieve greater reliability and validity. The use of these multiple sources helped to corroborate the results of the data collected.

\subsection{Collection of Authentic Workplace Texts}

Throughout the investigation, and in fact as an on-going process, merchandisers have provided samples of correspondence they have written or received. This has enabled an analysis of the writing style of these authentic texts to be carried out.

\subsection{Visits to the Workplace}

The authors visited the administrative office of a Hong Kong-based buying office for half a day to obtain an understanding of the operation of the company and to observe merchandisers at work. Two days were spent at the company's large factory just outside Shenzhen, a city in China close to Hong Kong, to observe the procedures involved and the communications required in the production of garments.

\section{Findings}

The surveys showed substantial use of English, but with far greater use of written compared with spoken English.

This question aimed to gain an appreciation of the range of countries with which Hong Kong companies trade and it was found that 46 different countries were mentioned.

China was most frequently mentioned in both surveys followed by the USA. Other major trading countries included Japan, Macau, Taiwan, Korea, Canada, Italy and the UK.

Even though English is not the first language of many of these countries, the international language of business, English, is used by the Hong Kong merchandisers in their communications with most of them. Only with China, Taiwan and Macau is it possible for communications to be carried out in Chinese.

While the survey results indicate the extensive range of countries merchandisers may need to communicate with, the countries will obviously vary according to individual business contacts at any time.

Not surprisingly, fax was rated as the most common channel 
in each survey, followed closely by the telephone. E-mail was not very widely used at the time these surveys were conducted; however, it is becoming an increasingly popular channel and further investigations are being carried out to determine current usage.

Three activities were ranked highly, and in the same order, in both surveys.

They were:

1 following up on an order;

2 advising updated order status;

3 clarifying order queries.

4 negotiating for better order terms;

5 negotiating or settling a claim;

6 making a claim.

The identification of the most frequently required written communication activities has provided an insight into the specific communication needs of these merchandisers and as a result, teaching and learning materials have been developed to provide practice in such activities.

Respondents were asked if they used abbreviations in their own written communications. They were also asked to provide ten examples of abbreviations used and the table below gives the most frequently mentioned from over 370 examples given.

1 the use of standard abbreviations, am/pm;

2 the use of abbreviations for two or more words;

3 the use of abbreviations typically associated with telexes, adv., u.

Table 2. The most frequently mentioned abbreviations.

\begin{tabular}{ll}
\hline $\mathrm{PLS}=$ please & $\mathrm{SMPL}=$ sample \\
$\mathrm{ASAP}=$ as soon as possible & $\mathrm{GMT}=$ garment \\
$\mathrm{CFM}=$ confirm & $\mathrm{B} / 4=$ before \\
$\mathrm{ADV}=$ advise & $\mathrm{PX}=$ price \\
$\mathrm{TKS}=$ thanks & $\mathrm{U}=$ you \\
\hline
\end{tabular}

The current collection of over 100 samples of authentic written correspondence, mostly in the form of faxes, has provided an insight into the type of communications common in textile and clothing merchandising. Features of particular interest are discussed below:

\subsection{Presentation of the Message}

Use of uppercase letters was noticed. A number of examples were printed entirely in uppercase letters. Such a style is not easy to read and students have been alerted not to use this type of writing.

\subsection{Paragraphing}

This varied in the samples collected, with some short paragraphs of just one or two lines through to solid blocks of text of more than 30 typed lines. Students are advised to follow the recommended paragraph length given in many business communication texts.

\subsection{Headings and Paragraph Numbering}

These features, which were in evidence in some samples, made the messages easier to read. Students are advised to consider their use so as to improve the appearance of the message and to ease comprehension.

\subsection{Abbreviations}

Almost all of the sample texts collected used abbreviations and this supports the survey findings which showed over an $85 \%$ usage. Student activities to practice comprehension and production of abbreviations are now included in the programs.

\subsection{Grammatical Accuracy}

Examples of grammatical errors noted in the texts include a number of common errors made by students in Hong Kong and a selection of these follows.

- Noun/adjective confusion: JAPAN SUPPLIER should read JAPANESE SUPPLIER.

- Verb tense: PLS NOTED should read PLS NOTE; AFTER OUR BUYER SEE should read AFTER OUR BUYER SAW.

- Word order for questions: WHAT WE CAN DO? should read WHAT CAN WE DO?

\subsection{Tone}

The use of an appropriate tone was mentioned as an important issue by the supervisors. This facilitates an effective relationship being built between the merchandiser and the customer.

YOU JUST PURCHASE ...

YOU MUST ADVISE ... AND MUST DEDUCT ...

YOU MUST TAKE FULL RESPONSIBILITY.

Awareness of the impact of such negative, accusative language is an important language teaching area now included in the teaching programs, particularly as a result of the comments made by the supervisors.

\subsection{Business Jargon}

Examples of out-dated business jargon were noted in the sample correspondence, e.g. 'herewith', 'Please be informed that . . .', 'It has been brought to our attention that . . .', 'Please contact the undersigned.' ,etc.

Hong Kong business writing guides advise against the use of such jargon.

\subsection{Connectives}

The use of connectives, while effective in linking ideas in a message, were often over-used in the sample correspondence or used inappropriately. e.g. 'anyway, so, further, but, also'.

Students are alerted to the possible overuse of such words.

\subsection{Incomplete Sentences}

Incomplete sentences noted in some correspondence can imply a careless attitude towards the work in hand and may lead to misunderstandings. 


\section{Conclusion}

In this review we studied the professional language needs of university graduates as seen by prospective employers. The findings confirm that foreign language skills are an increasingly important basic component of professional academic skills, particularly in countries which have major business contacts with the world and their native languages are not among the major world languages. Close cooperation with employers in planning language courses is thus needed in order to tailor language teaching to adequately meet the needs of the future academic workforce. This again may call for attitude change in language programs as language teaching has tended to be geared towards the academic needs of students, or considered as contributing to their personal development. Responding to workplace needs has not always been a clear target despite the long tradition of LSP/ESP. A clear message from the employers was the need for language centers to see language skills from a wider perspective essentially including skills such as fluent presentation and interaction, use of a lingua franca or lingua francas, confidence to communicate in a variety of situations, cultural competence, and learning-to-learn skills.

As shown by Forey (2004), the manner in which the theme or the thematic choice is interpreted can be used in order to raise the awareness about the pedagogy of writing in the workplace.

In effect, this means that university students starting to learn a new language should be encouraged to continue their studies in that language to a level that enables them to actually use the language effectively. It is therefore important to start as early as possible, preferably in the first year of university, and be systematic about the study. This goal also places increasing demands on course design and development as well as on study guidance.

An effective and flexible ESP course design can be produced from the teachers own practical experiential knowledge and from the students themselves. This may be more effective than following explicit directions as to how to do needs analysis and build ESP curricula. Authentic texts in the media, and widely available international textbooks published for various fields can be used selectively and efficiently according to the specific needs of particular students in an ESP context. Syllabus design is influenced not only by the target situation but also by many other factors that make it dynamic and interactive to maximize learning.

We believe that our findings may be generalized to other countries with a similar language situation. However, more research is needed in other contexts.

\section{References}

[1] G. Crosling, and I. Ward, "Oral communication: the workplace needs and uses of business graduate employees," English for specific purposes, 21, pp. 41-57, 2002.
[2] N. Edwards, "Language for business: effective needs assessment, syllabus design and materials preparation in a practical ESP case study," English for Specific Purposes, 19, pp. 291-296, 2000.

[3] G. Forey, "Workplace texts: do they mean the same for teachers and business people? English for Specific Purposes, 23, pp. 447-469, 2004.

[4] H. Kassim, and F. Ali, "English communicative events and skills needed at the workplace: Feedback from the industry," English for Specific Purposes, 29, pp. 168-182, 2010.

[5] M. A. Moslehifar, and N. A. Ibrahim, "English Language Oral Communication Needs at the Workplace: Feedback from Human Resource Development (HRD) Trainees," Procedia Social and Behavioral Sciences, 66, pp. 529 - 536, 2012.

[6] R. Horppu, and R. Niskanen, (eds), "Final Report on the Evaluation of Education in Language and Communication Skills. Evaluation projects of the University of Helsinki," 23, 2004.

[7] G. Stivers, J. Campbell, and H. Hermanson, “An Assessment Program for Accounting: Design, Implementation, and Reflection," Issues in Accounting Education, Vol. 15, No.4, pp. 553-581, 2000.

[8] D. Blair, and S. Jeanson, "Workplace Oral Communication Curriculum. Winnipeg, MB: Workplace Education Manitoba Steering Committee, Manitoba Department of Education and Training," Continuing Education Division, 1995.

[9] N. Fairclough, "Discourse and Social Change," Cambridge: Polity Press, 1995.

[10] M. Foucault, "The order of discourse. In M. J. Shapiro (ed) Language and politics," Oxford: Blackwell, 1984.

[11] P. Bourdieu, and L. Wacquant, "An Invitation to Reflexive Sociology,” Cambridge: Polity Press, 1992.

[12] J. Habermas, "The theory of communicative action," Boston: Beacon Press, 1987.

[13] A. Cicourel, "The interpenetration of communicative contexts: examples from medical encounters. In A. Duranti \& C. Goodwin (eds)", Rethinking Context: Language as as an Interactive Phenomenon, 291 - 310. Cambridge: CUP, 1992.

[14] J. Martin, and D. Rose, "Working with Discourse - Meaning beyond the Clause," London \& New York: Continuum, 2003.

[15] M. J. St John, "Business is booming: business English in the 1990's. English for Specific Purposes," 15(1), 3-18, 1996.

[16] J. M. Swales, "Languages for specific purposes," Annual Review of Applied Linguistics, 20, 59-76, 2000.

[17] M. Hewings, "Editorial," English for Specific Purposes, 21(3), 209-210, 2002. 